\title{
Identification and characterization of microsatellites from the Antarctic isopod Ceratoserolis trilobitoides: nuclear evidence for cryptic species
}

\author{
Florian Leese $\cdot$ Christoph Held
}

Received: 5 December 2007 / Accepted: 7 December 2007

(C) Springer Science+Business Media B.V. 2008

\begin{abstract}
We report the successful isolation of 10 polymorphic microsatellite markers for one species of the marine isopod species complex Ceratoserolis trilobitoides (Eights, 1833) from the Southern Ocean. The number of alleles per locus ranged from 6 to 30 for the 148 specimens analysed and heterozygosity ranged from 0.34 to 0.98 . Seven microsatellites amplified successfully in a cryptic sister species, which is restricted to the Antarctic Peninsula. This novel marker set provides the opportunity to study and monitor population structure, demography and gene flow patterns for a benthic model taxon in a region that is now subject to rapid climate change.
\end{abstract}

Keywords Southern Ocean - Benthos - Serolidae · Cryptic species - Microsatellite isolation .

Population genetics

The species Ceratoserolis trilobitoides (Eights, 1833) is a large and locally abundant model invertebrate for ecological, physiological and biogeographic studies on the High Antarctic shelf (e.g. Clarke and Gore 1992; Luxmoore 1981; Clarke 1984; Wägele 1987; Brandt 1991). Recent molecular genetic studies have shown that $C$. trilobitoides sensu Wägele (1986) in fact consist of at least two cryptic species that differ in their distribution ranges, ecological

F. Leese $(\bowtie) \cdot$ C. Held

Alfred Wegener Institute for Polar and Marine Research,

P.O. Box 12 0161, 27515 Bremerhaven, Germany

e-mail: florian.leese@awi.de

F. Leese

Department of Animal Ecology, Evolution and Biodiversity,

Ruhr-University of Bochum, Universitaetsstrasse 150,

44780 Bochum, Germany preferences and morphology (Held 2003; Held unpubl. data). One of these species represents the type, Ceratoserolis trilobitoides sensu stricto (Eights, 1833, group 2 in Held 2003) which is restricted to the Antarctic Peninsula. The other, broadly distributed species, Ceratoserolis $\mathrm{n}$. sp. 1 (group 1 in Held 2003), is new to science (species description Held in prep.). This study reports the successful development of ten microsatellite markers for Ceratoserolis n. sp. 1. In addition, the utility of the microsatellite in the cryptic type species Ceratoserolis trilobitoides s. str. is tested.

Material was collected on expeditions ANTXIII/3 and ANTXIV/2 to the Antarctic with "RV Polarstern". Specimens of Ceratoserolis n. sp. 1 were collected with Agassiz trawls near Elephant Island (population 1, $n=78$ ), King George Island (population 2, $n=47$ ) and from the eastern Weddell Sea (population 3, $n=33$ ). Specimens of C. trilobitoides $\mathrm{s}$. str. were collected near Elephant Island (population $4, n=8$, Fig. 1).

Genomic DNA from specimens of Ceratoserolis n. sp. 1 was isolated from ethanol preserved muscle tissue using standard spin column protocols (Qiagen DNeasy). A genomic library enriched for microsatellites was created using the reporter genome protocol (Nolte et al. 2005) as described in Held and Leese (2007). Hybridization chips (Hybond N+, GE Healthcare) with single stranded genomic DNA from Mus musculus, Drosophila melanogaster (strain Canton S) and Homo sapiens as reporter genomes were used as natural enrichment probes (reporter genomes). Enriched fragments were ligated into pCR2.1 TOPO vectors (Invitrogen) and transformed into E. coli (Promega JM 109, Invitrogen TOP10F'). Positive clones were grown overnight in LB media. Alternatively, plasmids were directly amplified using Eppendorf OriMaster Kit. Sequencing was conducted on a LI-COR 4200, an ABI 3130xl automated sequencer 


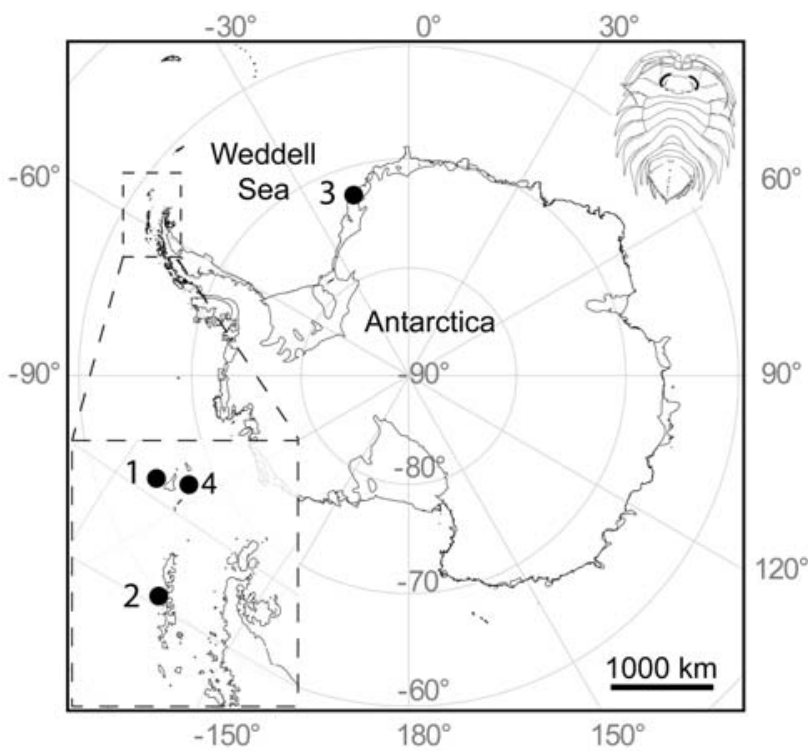

Fig. 1 Sampling sites for specimens of Ceratoserolis trilobitoides sensu Wägele (1986): The cryptic species Ceratoserolis n. sp. 1 was sampled at stations 1-3, specimens of the Ceratoserolis trilobitoides s. str. at station 4. Drawing of Ceratoserolis n. sp. 1 from $\mathrm{CH}$

or by Macrogen Inc. (Korea). Sequence analysis was conducted manually using the software LASERGENE (DNAStar Inc.).

From the partial genomic libraries enriched using Mus musculus, Drosophila melanogaster and Homo sapiens as enrichment templates we obtained 171, 91 and 62 unique inserts with microsatellites, respectively $(\varnothing 88 \%$ positive clones). Flanking primers for 50 candidate loci were designed using FastPCR (Kalendar 2003). Primer pairs were tested in $20 \mu \mathrm{l}$ reactions on a gradient cycler (PTC200 , MJ research) with annealing temperatures from $48^{\circ} \mathrm{C}$ to $65^{\circ} \mathrm{C}$. The PCR protocol was $2 \mathrm{~min}$ at $94^{\circ} \mathrm{C}$ followed by 36 cycles of $20 \mathrm{~s}$ at $94^{\circ} \mathrm{C}, 15 \mathrm{~s}$ at annealing temperature (Table 1), $30 \mathrm{~s}$ at $65^{\circ} \mathrm{C}$, plus a final extension step of $5 \mathrm{~min}$ at $65^{\circ} \mathrm{C}$. PCR reagents: $0.2 \mathrm{mM}$ dNTPs, $0.5 \mu \mathrm{M}$ primer (unlabeled), $0.5 \mathrm{M}$ Betaine, $2.5 \mathrm{mM} \mathrm{MgCl}, 0.03 \mathrm{U} / \mu \mathrm{l}$ Hotmaster Taq (Eppendorf), 2-40 ng DNA. Twenty-seven of the 50 loci yielded amplification products and were investigated for their utility for population genetic studies. To this end, PCR reactions were performed as above substituting one unlabeled primer with a $5^{\prime}$-fluorescently labeled primer (Table 1). Additionally, the number of cycles was reduced to 30-32 and a final elongation step of $45 \mathrm{~min}$ at $65^{\circ} \mathrm{C}$ was added in order to reduce in vitro artefacts. Subsequently, $1 \mu \mathrm{l}$ of diluted PCR product ( 2 to 15-fold in molgrade $\mathrm{H}_{2} \mathrm{O}$ ) was denatured in a mixture of $14.7 \mu \mathrm{l} \mathrm{HI}-\mathrm{DI}$ formamide and $0.3 \mu \mathrm{l}$ GeneScan ROX 500 size standard (Applied Biosystems). Fragments were analyzed on an ABI 3130xl sequencer. Genotyping was performed using GENEMAPPER v4.0 (Applied Biosystems).
For Ceratoserolis n. sp. 1 ten of the 27 candidate loci were scoreable and polymorphic (GenBank accession numbers EU294218-EU294227). As many as 17 loci were discarded, as they were either monomorphic, revealed strong in vitro artefacts ('stutter bands'), amplified more than two alleles per individual or could not be reliably genotyped.

Microsatellite variability for the ten suitable markers was evaluated using specimens from populations 1-3 (Fig. 1). All loci were examined for genotyping errors, allelic dropout and null alleles using MICRO-CHECKER 2.2.3 (van Oosterhout et al. 2004) and DROPOut (McKelvey and Schwartz 2005). Tests for Hardy-Weinberg equilibrium (HWE) were performed using ARLEQUIN 3.11 (Excoffier et al. 2005) and for genotypic disequilibrium using GENEPOP 4.0.6 (Rousset 2007). The unbiased probability of identity for all 148 specimens was calculated using GIMLET 1.3.3 (Valiere 2002).

The number of alleles per locus ranged from 6 to 30 . The observed heterozygosity ranged from 0.34 to 0.98 . No evidence for global genotypic disequilibrium was found across all pairs of loci across all samples (fisher's exact method). After sequential Bonferroni correction (Rice 1989) only loci C1H93 and C1Df14 deviated from HWE $(P<0.01)$ with significantly reduced heterozygosities (Table 1). This inflated homozygosity most likely from the presence of null alleles as inferred from analyses using MICRO-CHECKER. The overall probability of identity for the data set investigated $(n=148)$ is high, PI $=2.920 \times 10^{-15}$.

Amplification success of the ten microsatellites was tested in the type $C$. trilobitoides $\mathrm{s}$. str. from Elephant Island (population 4, Fig. 1). Seven microsatellites amplified successfully of which five markers showed private alleles (Table 2). Consequently, eight of the ten microsatellite markers developed in this study add support from the nuclear genome to the hypothesis that Ceratoserolis n. sp. 1 and $C$. trilobitoides s. str. represent two reproductively isolated species, as suggested on the basis of mitochondrial (Held 2003) and morphological data (Held in prep.).

This marker set provides sufficient resolution for detailed population genetic, phylogeographic and molecular ecological studies on these two benthic key taxa in the Southern Ocean. These findings are especially important to understand the microevolutionary causes of frequent, often cryptic, speciations in benthic taxa inhabiting the High Antarctic shelf (Held 2000, 2003; Held and Wägele 2005; Wilson et al. 2007). Data collected on population structure and demography of these benthic key species is additionally of major importance to study and monitor the consequences of global and regional warming on the Antarctic biota that inhabit one of the world's most affected regions to climate change (Vaughan et al. 2003; Meredith and King 2005). 


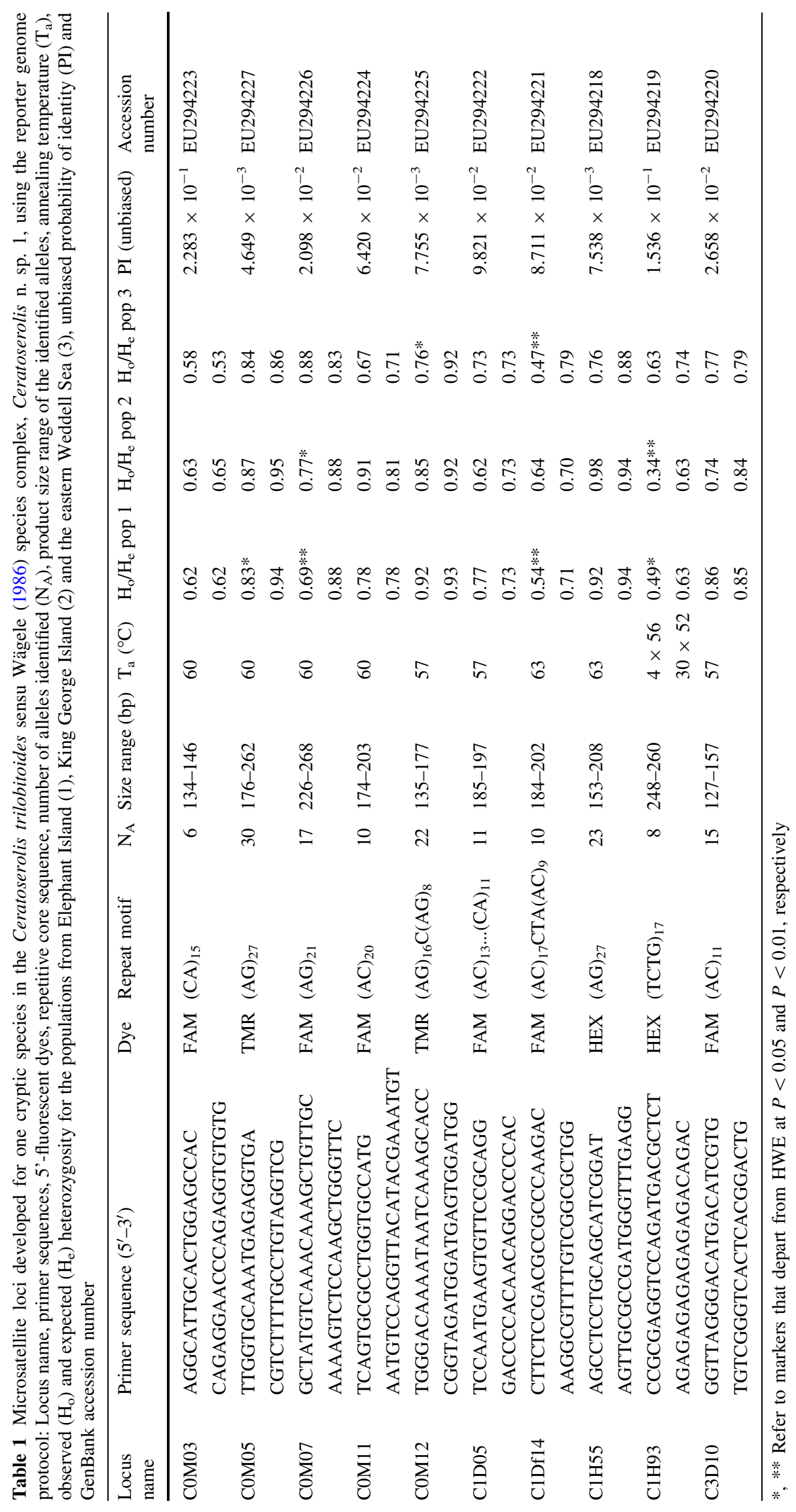


Table 2 Cross-amplification success and product length ranges of microsatellite markers in the species $C$. trilobitoides s. str. from Elephant Island $(n=8)$. The length range of the markers in Ceratoserolis $\mathrm{n}$. sp. 1 are shown for comparison

\begin{tabular}{lcll}
\hline $\begin{array}{l}\text { Locus } \\
\text { name }\end{array}$ & $\begin{array}{l}\text { Amplification } \\
\text { success }\end{array}$ & $\begin{array}{l}\text { Range (bp) } \\
\text { 'C. trilobitoides } \\
\text { s.str.' }\end{array}$ & $\begin{array}{l}\text { Range } \\
\text { (bp) } \\
\text { 'C. dinae' }\end{array}$ \\
\hline C0M03 & - & - & $134-146$ \\
C0M05 & + & $218-230$ & $176-262$ \\
C0M07 & + & $301-305$ & $226-268$ \\
C0M11 & + & $167-187$ & $174-203$ \\
C0M12 & + & $121-141$ & $135-177$ \\
C1D05 & + & $185-209$ & $185-197$ \\
C1Df14 & - & - & $184-202$ \\
C1H55 & + & $170-201$ & $153-208$ \\
C1H93 & - & - & $248-260$ \\
C3D10 & + & $129-161$ & $127-157$ \\
\hline
\end{tabular}

Acknowledgements We thank Wolfgang Wägele (Museum Koenig, Bonn, Germany) and Tilman Alpermann (AWI Bremerhaven, Germany) for helpful discussions and Andrea Eschbach for technical assistance. Anna Kop (York University, Toronto, Canada) proofread an earlier version of the manuscript. This work was supported by a DFG grant HE-3391/3 to Christoph Held.

\section{References}

Brandt A (1991) Colonization of the Antarctic shelf by the Isopoda (Crustacea, Malacostraca). Ber Polarforsch 98:1-240

Clarke A (1984) Lipid composition of two species of Serolis (Crustacea, isopoda) from Antarctica. Br Antarct Surv Bull 64:37-53

Clarke A, Gore DJ (1992) Egg size and composition in Ceratoserolis (Crustacea: Isopoda) from the Weddell Sea. Polar Biol 12:129-134

Excoffier L, Laval G, Schneider S (2005) Arlequin ver. 3.0: an integrated software package for population genetics data analysis. Evol Bioinform Online 1:47-50

Held C (2000) Phylogeny and biogeography of serolid isopods (Crustacea, Isopoda, Serolidae) and the use of ribosomal expansion segments in molecular systematics. Mol Phylogenet Evol 15:165-178

Held C (2003) Molecular evidence for cryptic speciation within the widespread Antarctic crustacean Ceratoserolis trilobitoides (Crustacea, Isopoda). In: Huiskes AHL, Gieskes WWC, Rozema J,
Schorno RML, van der Vies SM, Wolff WJ (eds) Antarctic biology in a global context. Backhuys Publishers, Leiden, pp 135-139

Held C, Leese F (2007) The utility of fast evolving molecular markers for studying speciation in the Antarctic benthos. Polar Biol 30:513-521

Held C, Wägele J-W (2005) Cryptic speciation in the giant Antarctic isopod Glyptonotus antarcticus (Isopoda: Valvifera: Chaetiliidae). Sci Mar 69:175-181

Kalendar R (2003) FastPCR: a program for fast design PCR primer, DNA and protein manipulation (version 2.5.59). Institute of Biotechnology, University of Helsinki

Luxmoore RA (1981) The ecology of Antarctic serolid isopods. Council for National Academic Awards, pp 1-231

McKelvey KS, Schwartz MS (2005) DROPOUT: a program to identify problem loci and samples for noninvasive genetic samples in a capture-mark-recapture framework. Mol Ecol Notes 5:716-718

Meredith MP, King JC (2005) Rapid climate change in the ocean west of the Antarctic Peninsula during the second half of the 20th century. Geophys Res Lett 32:L19604

Nolte AW, Stemshorn KC, Tautz D (2005) Direct cloning of microsatellite loci from Cottus gobio through a simplified enrichment procedure. Mol Ecol Notes 5:628-636

Rice WR (1989) Analyzing tables of statistical tests. Evolution 43:223-225

Rousset F (2007) GENEPOP '007: a complete reimplementation of the GENEPOP software for Windows and Linux. Mol Ecol Notes (online first). doi:10.1111/j.1471-8286.2007.01931.x

Valiere N (2002) GIMLET: a computer program for analysing genetic individual identification data. Mol Ecol Notes 2:377-379

van Oosterhout C, Hutchinson WF, Wills DPM, Shipley P (2004) MICRO-CHECKER: software for identifying and correcting genotyping errors in microsatellite data. Mol Ecol Notes 4: 535-538

Vaughan DG, Marshall GJ, Connolley WM, Parkinson C, Mulvaney R, Hodgson DA, King JC, Pudsey CJ, Turner J (2003) Recent rapid regional climate warming on the Antarctic Peninsula. Clim Change 60:243-274

Wägele J-W (1986) Polymorphism and distribution of Ceratoserolis trilobitoides (Eights, 1833) (Crustacea, Isopoda) in the Weddell Sea and synonymy with $C$. cornuta (Studer, 1879). Polar Biol 6:127-137

Wägele J-W (1987) On the reproductive biology of Ceratoserolis trilobitoides (Crustacea: Isopoda): latitudinal variation of fecundity and embryonic development. Polar Biol 7:11-24

Wilson NG, Hunter RL, Lockhart SJ, Halanych KM (2007) Multiple lineages and absence of panmixia in the "circumpolar" crinoid Promachocrinus kerguelensis from the Atlantic sector of Antarctica. Mar Biol 152:895-904 